\title{
Endoscopic Snare Excision of a Major Duodenal Papillary Tumor
}

\author{
Yoshinori Igarashi Naoki Okano Ken Ito Takahiko Mimura Shigeru Nakano \\ Division of Gastroenterology and Hepatology, Department of Internal Medicine, School of Medicine, \\ Faculty of Medicine, Toho University, Tokyo, Japan
}

\section{Key Words}

Biliary stenting $\cdot$ Endoscopic snare excision $\cdot$ Major

duodenal papillary tumor $\cdot$ Pancreatic stenting

\begin{abstract}
Background/Aims: Tumors of the duodenal papilla include hyperplasia, adenoma, carcinoma in adenoma, and carcinoma. Since the duodenal papilla has special anatomical characteristics and treatment involves major intervention, a correct preoperative diagnosis is essential for successful treatment. Methods: In patients with adenoma or early carcinoma of the papilla, endoscopic snare excision is indicated for complete removal of the tumor. Postoperative pancreatitis and cholangitis are major complications of endoscopic techniques, and we describe here in detail our procedure aiming to reduce the incidence of such complications. Results: Endoscopic snare excision of a tumor of the major duodenal papilla was carried out in 36 patients. Bleeding after endoscopic excision occurred in 6 cases (17\%), postoperative pancreatitis in 11 cases (30\%), and postoperative cholecystitis in 1 case (3\%). All patients recovered from the complications within 1 week. Conclusion: Our results suggest that the procedure for endoscopic snare excision used to resect major papillary tumors is safe and helps to prevent serious complications.

Copyright $\odot 2010$ S. Karger AG, Basel
\end{abstract}

\section{Introduction}

Tumors of the duodenal papilla can include adenomas, carcinoma in adenomas and carcinomas, or show hyperplasia. Villous adenomas of the major papilla are complicated by carcinoma in about $30 \%$ of cases $[1,2]$, and treatment consists of local surgical resection. Prior to surgery, it is critical to establish a diagnosis of either benign or malignant disease, and the depth of invasion. In recent years, endoscopic papillectomy has been performed to achieve complete resection of adenomas [3, 4]. A number of endoscopic resection techniques for tumors of the major papilla have been introduced together with instruments developed for these purposes $[5,6]$. Such techniques can result in serious complications, such as bleeding and postoperative pancreatitis or postoperative cholangitis. In this paper, we introduce a technique for endoscopic snare resection of major papillary tumors using a polypectomy snare and postoperative stenting of the pancreatic and bile ducts, which appears to reduce the incidence of serious complications.

\section{Patients and Methods}

Indications

Patients underwent abdominal computer tomography, endoscopic ultrasonography (EUS), intraductal ultrasonography (IDUS) and endoscopic retrograde cholangiopancreatography (ERCP) prior to endoscopic treatment. The indications for endoscopic snare excision were as follows: (1) the tumor is a protruding

\section{KARGER}

Fax +41613061234 E-Mail karger@karger.ch www.karger.com
Yoshinori Igarashi, $\mathrm{MD}, \mathrm{PhD}$

Division of Gastroenterology and Hepatology, Department of Internal Medicine

School of Medicine, Faculty of Medicine, Toho University

6-11-1 Omorinishi, Ohta-ku, Tokyo 143-8541 (Japan)

Tel. +81 33762 4151, Fax +8133763 8542, E-Mail igarashi@ med.toho-u.ac.jp 

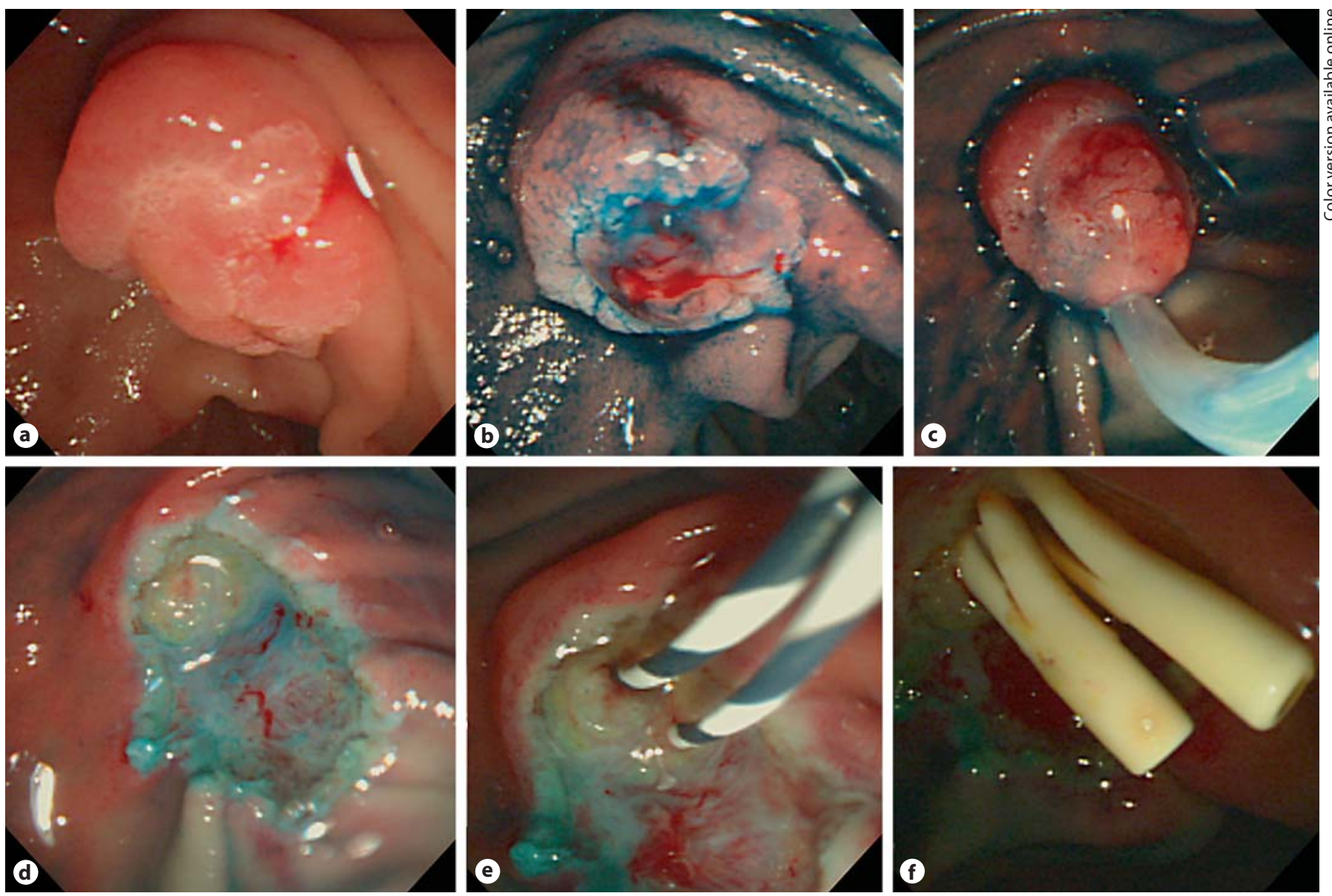

Fig. 1. A 77-year-old woman who was admitted to our hospital with abdominal discomfort. a Endoscopy shows swelling of the major papilla, and histological examination of the biopsy specimen reveals adenoma. b Dye endoscopy (indigo carmine) clearly indicates the tumor margins. c The polypectomy snare is opened from the oral side of the tumor, and the wire is tightened while observing the anal side. $\mathbf{d}$ The tumor is resected with high-fre-

quency surgical equipment set at $120 \mathrm{~W}$ in the Autocut mode (pure cutting current). Endoscopic image shows no bleeding and no perforation after resection. e The guide wire inserted into the pancreatic and bile duct. f A 7-french pancreatic stent was inserted into the pancreatic duct and a 7-french biliary stent was also inserted into the common bile duct.

lesion without ulceration; (2) histological findings of a biopsy specimen showed hyperplasia, atypical epithelium and adenoma, with endoscopic snare excision being indicated for the treatment of adenocarcinoma but not carcinoma at that time; (3) ERCP findings are normal for the main pancreatic duct and the common bile duct; (4) the tumor is located in the mucosal layer (determined by EUS), and (5) IDUS findings are normal for the main pancreatic duct and the common bile duct, and reveal no tumor invasion of the sphincter of Oddi.

\section{Patients}

Thirty-six patients (18 males and 18 females; mean age, 66 years; range 34-89 years) with tumor of the major duodenal papilla were admitted to our hospital during the period from October 2002 to March 2009. Tumor size was $16.3 \pm 7.4 \mathrm{~mm}$ (mean \pm

SD, range: 7-34 mm). Informed consent was obtained from all patients prior to endoscopic treatment.

\section{Endoscopic Technique}

ERCP is performed using a TJF-240 or TJF-260V duodenoscope (Olympus, Tokyo, Japan). For tumor resection, first indigo carmine is sprayed over the tumor to demarcate it (fig. la, b), and a polypectomy snare (SD-Y0001-U15 or SD-230U; Olympus) is placed over the tumor from the oral side. The snare wire is then tightened while observing the anal side of the tumor. The wire is subsequently slackened and gently pulled up and down in order to prevent perforation due to inclusion of the muscular coat within the snare (fig. 1c). The tumor is then resected en block with high-frequency surgical equipment (PSD-60; Olympus) set at $120 \mathrm{~W}$ in the Autocut mode (effect 6). Care is taken when making the incision line on the 
Table 1. Early and late complications in the study patients treated with endoscopic snare excision

\begin{tabular}{lc}
\hline Early complications & \\
Bleeding: endoscopic hemostases & \\
During the procedure & 3 cases \\
On the next day & 2 cases \\
After 7 days & 1 case \\
Total & 6 cases \\
Postoperative pancreatitis & 11 cases \\
Acute cholecystitis & 1 case \\
Perforation & 0 case \\
\hline Late complications & \\
Stenoses & \\
Pancreatic and biliary duct & 1 case \\
Biliary tract & 1 case \\
Total & 2 cases \\
\hline
\end{tabular}

anal side of the tumor, as there is no supportive tissue such as the pancreas, and a wide incision may perforate the duodenum.

Immediately after resection, the orifice of the common bile duct located at the upper side of the major papilla should be confirmed (fig. 1d), followed by the orifice of the pancreatic duct, which is typically noted just right of or to the anal side of the bile duct opening. After checking the pancreatic duct orifice, the course of the main pancreatic duct is determined with the aid of a small amount of contrast medium, and a 7-french pancreatic stent is then placed. A 7-french biliary stent is also inserted into the common bile duct (fig. 1e, f).

Patients fasted for 3 days after tumor resection, and antibiotic and anti-enzyme drugs were administered. Plain abdominal Xrays were obtained the day after endoscopic resection. Laboratory tests were performed daily. If all findings were normal, oral administration of water and food was started on day 4 .

ERCP was repeated on day 7 in order to remove the pancreatic and biliary stents. All patients attended follow-up 6 months and 1 year after surgery.

\section{Results}

\section{Early Complications}

Early complications (table 1) that can arise following endoscopic papillectomy for a papillary tumor are (1) bleeding, (2) postoperative pancreatitis, (3) postoperative acute cholangitis, and (4) perforation [7]. In our series, bleeding occurred in 6 cases (17\%) after endoscopic snare extraction. In 3 of the 6 cases, bleeding could be stopped using a hemoclip and/or electric coagulation.

Bleeding occurred on postoperative day 1 in 2 cases and on postoperative day 7 in the remaining case. In all cases, bleeding was successfully stopped.

Endoscopic Snare Excision of Papillary

Tumors
Postoperative pancreatitis occurred in 11 cases (30\%) and postoperative acute cholecystitis in 1 case. All patients were treated conservatively and recovered by postoperative day 7. No case of perforation occurred.

\section{Late Complications}

Late complications encountered were (1) stenosis of the major papilla (table 1) and (2) tumor recurrence.

In regard to stenosis, 2 cases (5.5\%) showed stenosis of the main papilla: one of the main pancreatic duct and the bile duct, and the other of the bile duct. Additional endoscopic sphincterotomy or balloon dilation was successful in both cases.

Regarding tumor recurrence, there was no recurrence of adenoma. Recurrence of adenocarcinoma in adenoma (25\%) was diagnosed in 1 case after 3 months and endoscopic snare resection was repeated. The patient showed no recurrence after 30 months. In addition, recurrence was found in 2 adenocarcinoma cases (40\%). One of the patients died from metastatic disease after 13 months, and the other patient is doing well 37 months after endoscopic biliary stenting.

\section{Discussion}

Screening endoscopy of the upper gastrointestinal tract using a forward-viewing scope has recently been utilized to facilitate the diagnosis of tumors of the major duodenal papilla. However, the tumor can be difficult to visualize from the front. In such cases, the side-viewing scope is a useful and important tool to observe the major papilla. Tumors of the duodenal papilla can include adenomas, carcinoma in adenomas, carcinomas, carcinoids, or hemangiomas, or show hyperplasia, and a correct preoperative diagnosis is important to select the most suitable treatment approach. While tubular adenoma of the major papilla is rarely associated with adenocarcinoma, villous adenoma is complicated by carcinoma in about $30 \%$ of cases [2]. In patients with carcinoma in adenoma, it is extremely difficult to make a definitive diagnosis from a biopsy specimen because the carcinoma cells are located deep within the tumor. Using EUS, it is possible to determine the localization of a tumor in the duodenal wall [8] and with IDUS, it is possible to clarify possible invasion of the main pancreatic and/or common bile ducts [9]. We found that ERCP, EUS and IDUS were useful to determine the depth of tumor invasion before endoscopic treatments. Endoscopic snare excision performed according to our indi-

Dig Surg 2010;27:119-122 
cations was found to be successful in reducing the incidence of serious complications in our series of $36 \mathrm{pa}-$ tients. Furthermore, since en block resection is known to be more beneficial than biopsy for histological diagnosis in more severe, atypical cases [10], for 12 of our patients (33\%) who were preoperatively diagnosed with carcinoma in adenoma or carcinoma requiring major intervention, the polypectomy snare, which enables complete resection for confirmatory histological diagnosis, is clearly advantageous.

\section{Conclusion}

Using our technique involving a polypectomy snare, which reduced the need for intra- and postoperative stenting of the pancreatic and/or bile duct, serious complications may be reduced thus improving the safety of endoscopic snare excision of a tumor of the major papilla. In addition, en block resection of the tumor is useful for histological diagnosis, which is especially important for patients diagnosed with adenocarcinoma as they require follow-up examinations and in some cases additional surgery.

\section{References}

1 Berger HG, Treitschke F, Gansauge F, Harada N, Hiki N, Mattfeldt T: Tumor of the ampulla of Vater. Experience with local or radical resection in 171 consecutively treated patients. Arch Surg 1999;134:526-532.

-2 Ryan DP, Schapiro RH, Warshaw AL: Villous tumors of the duodenum. Ann Surg 1986; 203:301-306.

3 Desilets DJ, Dy RM, Ku PM, Hanson BL, Elton E, Mattia A, Howell DA: Endoscopic management of tumors of the major duodenal papilla: refined techniques to improve outcome and avoid complications. Gastrointest Endosc 2001;54:202-208.
-4 Cantalano MF, Linder JD, Chak A, Sivak MV, Raijman I, Geene JE, Howell DA: Endoscopic management of adenoma of the major duodenal papilla. Gastrointest Endosc 2004 59:225-232.

-5 Igarashi Y, Okano N, Sato D, Itou K, Mimura T, Miura T, Iida K, Sumino Y, Miki K: Endoscopic snare excision for a major papilla tumor. Dig Endosc 2005;17:179-182.

-6 Aiura K, Imaeda H, Kitajima M, Kumai K: Balloon-catheter-assisted endoscopic snare papillectomy for benign tumors of the major duodenal papilla. Gastrointest Endosc 2003; 57:743-747.

7 Okano N, Igarashi Y, Miura T, Miki K: The study of early complications of endoscopic papillectomy of the tumor with duodenal major papilla (in Japanese with English abstract). J Jpn Biliary Assoc 2007;21:623-629.
8 Mitake M, Nakazawa S, Tsukamoto Y, Naitoh Y, Kimoto E, Hayashi Y: Endoscopic ultrasonography in the diagnosis of depth invasion and lymph node metastasis of carcinoma of the papilla of Vater. J Ultrasound Med 1990;9:645-650.

9 Itoh A, Goto H, Naitoh Y, Hiroka Y, Furukawa T, Hayakawa T: Intraductal ultrasonography in diagnosing tumor extension of cancer of the papilla of Vater. Gastrointest Endosc 1997;45:251-260.

10 Furukawa T, Ohashi Y, Watanabe Y, Yamao T, Katoh T, Yanagisawa A: The usefulness of endoscopic resection of the adenoma of the papilla of Vater (in Japanese with English abstract). Gastreoenterol Endosc 1999;41:284295. 